\title{
Магнитные свойства тонких эпитаксиальных слоев SiC, выращенных методом самосогласованного замещения атомов на поверхностях монокристаллического кремния
}

\author{
(C) Н.Т. Баграев ${ }^{1,2}$, С.А. Кукушкин ${ }^{1}$, А.В. Осипов ${ }^{1}$, В.В. Романов ${ }^{3}$, Л.Е. Клячкин ${ }^{2}$, \\ А.М. Маляренко ${ }^{2}$, В.С. Хромов ${ }^{1,2}$ \\ ${ }^{1}$ Институт проблем машиноведения Российской академии наук, \\ 199178 Санкт-Петербург, Россия \\ ${ }^{2}$ Физико-технический институт им. А.Ф. Иоффре Российской академии наук, \\ 194021 Санкт-Петербург, Россия \\ ${ }^{3}$ Санкт-Петербургский политехнический университет Петра Великого, \\ 195251 Санкт-Петербург, Россия \\ E-mail: bagraev@mail.ioffe.ru, sergey.a.kukushkin@gmai.com \\ Поступила в Редакцию 15 октября 2020 г. \\ В окончательной редакции 24 октября 2020 г. \\ Принята к публикации 24 октября 2020 г.
}

\begin{abstract}
Выполнен цикл экспериментальных исследований, а именно, проведены измерения и выполнен анализ полевых зависимостей статической магнитной восприимчивости в образцах тонких пленок монокристаллического $\mathrm{SiC}$, выращенных на поверхностях (100), (110) и (111) монокристаллического $\mathrm{Si}$ методом согласованного замещения атомов за счет химической реакции $\mathrm{Si}$ с газом CO. В результате исследований в структурах $\mathrm{SiC}$, выращенных на $\mathrm{Si}(110)$ и $\mathrm{Si}(111)$, обнаружено возникновение в слабых магнитных полях двух квантовых эффектов при комнатной температуре. Этими эффектами являются, во-первых, образование гистерезиса статической магнитной восприимчивости, а во-вторых, возникновение осцилляций АароноваБома в полевых зависимостях статической магнитной восприимчивости. Первый эффект связывается нами с эффектом Мейснера-Оксенфельда, а второй - с присутствием в данных структурах под слоем $\mathrm{SiC}$ микродефектов в виде нанотрубок и микропор, формирующихся в процессе синтеза структур. В структурах $\mathrm{SiC}$, выращенных на $\mathrm{Si}(100)$, эти эффекты обнаружены не были, что связывается нами с иным механизмом образования $\mathrm{SiC}$ на поверхности (100) $\mathrm{Si}$.
\end{abstract}

Ключевые слова: карбид кремния на кремнии, дилатационные диполи, магнитная восприимчивость, диамагнетизм, эффект Ааронова-Бома.

DOI: 10.21883/FTP.2021.02.50493.9538

\section{1. Введение}

В цикле работ [1-3] был разработан метод синтеза монокристаллических пленок $\mathrm{SiC}$ в приповерхностном слое $\mathrm{Si}$ за счет согласованного замещения атомов $\mathrm{Si}$ на атомы C с использованием химической реакции между монокристаллом $\mathrm{Si}$ и монооксидом углерода.

Подробное описание процессов, протекающих при выращивании $\mathrm{SiC}$ методом замещения атомов, и технологию его синтеза можно найти в обзорах $[4,5]$. Было обнаружено [1-5], что механизм согласованного замещения сохраняет строение исходной кубической решетки $\mathrm{Si}$, что обеспечивает рост именно кубического политипа 3C-SiC [4-6]. Это было подтверждено электронно-микроскопическими исследованиями, выполненными в работе [7], в которой также было показано, что дислокации несоответствия решеток на границе раздела $3 C$ - $\mathrm{SiC}(111) / \mathrm{Si}(111)$ отсутствуют. Вместо них на межфазной границе образуются дефекты упаковки с прослойками гексагональных фаз [4,7]. Этот результат показывает принципиальное отличие данного механизма роста пленок $\mathrm{SiC}$ от происходящего при выращивании другими методами, например методом химического осаждения из пара (CVD) [8]. Термин „согласованный“ означает, что удаление атома $\mathrm{Si}$ из решетки и встраивание атома $\mathrm{C}$ на его место за счет химической реакции

$$
2 \mathrm{Si}(\text { crystal })+\mathrm{CO}(\text { gas })=\mathrm{SiC}(\text { crystal })+\mathrm{SiO}(\text { gas }) \uparrow
$$

происходят одновременно [6]. Атом кислорода при этом играет роль катализатора реакции замещения. Переходное состояние реакции (1), отвечающее максимуму энергии вдоль пути реакции, представляет собой почти равносторонний треугольник с атомами $\mathrm{Si}, \mathrm{C}, \mathrm{O}$ в вершинах [6]. После преодоления этого барьера высотой 1.2 эВ молекула $\mathrm{SiO}$ покидает систему. Такой механизм согласованного замещения сохраняет строение исходной кубической решетки $\mathrm{Si}$, что обеспечивает рост именно кубического политипа $3 C-\mathrm{SiC}$ [5]. Эпитаксия пленок $\mathrm{SiC}$ на $\mathrm{Si}$ за счет согласованного замещения половины атомов $\mathrm{Si}$ на атомы C при отсутствии дислокаций несоответствия решеток обеспечивает высокое кристаллическое совершенство пленок $\mathrm{SiC}$ [4-7]. Реакция синтеза карбида кремния (1) протекает в две стадии. На первой стадии образуются комплексы кремниевая вакансиямежузельный атом углерода. На втором этапе углеродные атомы смещаются по направлению к кремниевым вакансиям, образуя карбид кремния. Активированные 
комплексы превращаются в карбид кремния, а освободившиеся вакансии сливаются в поры под слоем карбида кремния. В результате образуется пленка карбида кремния, частично висящая над порами в кремнии. Именно поэтому в пленках, полученных данным методом, отсутствуют упругие напряжения [1-7]. Ориентацию пленки при этом задает „старая“ кристаллическая структура исходной матрицы $\mathrm{Si}$, а не только поверхность подложки, как это обычно реализуется в традиционных методиках выращивания пленок.

В процессе согласованного замещения атомов происходит усадка материала или, как еще можно назвать этот процесс, „схлопывание“ исходной решетки материала $\mathrm{Si}$ с параметром 0.543 нм в кубическую решетку $\mathrm{SiC}$ с параметром 0.435 нм, которое происходит латерально, т. е. в плоскости подложки [4,7]. Дополнительные атомы $\mathrm{Si}$, необходимые для равномерного заполнения поверхности подложки, диффундируют из глубины подложки. Кроме того, использование силана $\left(\mathrm{SiH}_{4}\right)$ также является дополнительным средством получения равномерного слоя $\mathrm{SiC}$ толщиной $\sim 100 \mathrm{Hм}$ без пустот и ям $[4,5]$. Одновременно с этим механизмом образования слоя $\mathrm{SiC}$ происходит проникновение газа СО на большую глубину в подложку Si. Этот механизм реализуется за счет быстрого дрейфового, а не диффузионного, проникновения молекул газа СО как вдоль направлений $\langle 110\rangle$ кремния, так и вдоль дислокационных линий и других дефектов в исходной подложке кремния [9]. В результате внутри подложки под ровной пленкой $\mathrm{SiC}$ толщиной $~ 100 \mathrm{Hм}$ образуется слой пористого $\mathrm{SiC}$, представляющего собой комбинацию различных политипов $\mathrm{SiC}$ и нанотрубок $\mathrm{SiC}$. Толщина пористого $\mathrm{SiC}$ может достигать 3-10 мкм. Согласно реакции (1), объем образующегося $\mathrm{SiC}$ должен быть равен объему пустот в этом слое, поскольку объем одной ячейки $\mathrm{Si}$ в 2 раза больше объема одной ячейки $3 C$-SiC. Микрофотографии типичного среза $3 C-\mathrm{SiC}(111) / \mathrm{Si}(111)$ можно найти в работах $[1-7,9]$.

Удивительной особенностью данного метода выращивания $\mathrm{SiC}$ является то, что на границе раздела $\mathrm{SiC} / \mathrm{Si}$ возникает интерфейсный слой толщиной в несколько нанометров с нестандартными оптическими и электрофизическими свойствами. Необычные свойства вызваны тем, что на второй и завершающей стадии превращения кремния в карбид кремния происходит процесс усадки или „схлопывания“ материала, при котором карбид кремния как новая фаза отделяется от кремниевой матрицы. Кремний подвергается аномально сильному сжатию со стороны карбида кремния. Величина такого давления может доходить до 100 ГПа. При таких высоких давлениях не мог бы получиться $\mathrm{SiC}$ со столь хорошей структурой, если бы каждая пятая кристаллическая ячейка карбида кремния с высокой точностью не совпадала бы с каждой четвертой ячейкой кремния. В результате подобной усадки каждая пятая химическая связь $\mathrm{SiC}$ полностью согласуется с каждой четвертой связью $\mathrm{Si}$, остальные связи либо рвутся (отсюда и возникают вакансии и поры), либо подвергаются сжатию. Последнее приводит к изменению структуры поверхностных зон $\mathrm{SiC}$, прилегающего к $\mathrm{Si}$, и его превращению в „полуметалл“. Впервые это явление было недавно экспериментально обнаружено методом спектральной эллипсометрии в диапазоне энергий фотонов 0.5-9.3 эВ [10]. Экспериментальные исследования показали, что на границе раздела $3 C-\mathrm{SiC}(111) / \mathrm{Si}(111)$ образуется тонкий промежуточный слой с диэлектрической проницаемостью, соответствующей полуметаллу. Данный результат подтвержден квантово-химическим моделированием свойств межфазной границы раздела $3 C-\mathrm{SiC}(111) / \mathrm{Si}(111)$. Квантово-химические расчеты, выполненные в работе [10], показали, что в процессе бездислокационного согласования решеток $\mathrm{SiC}$ и $\mathrm{Si}$, различающихся на $20 \%$, пленка $\mathrm{SiC}$, обращенная к подложке $\mathrm{Si}$-поверхностью, притягивает один из 16 атомов $\mathrm{Si}$ в ближайшем двойном слое атомов подложки. При этом 22 из 25 атомов $\mathrm{Si}$ образуют химические связи с атомами $\mathrm{Si}$ подложки, а 3 атома из 25 (т.е. 12\%) связей не образуют, так как находятся слишком далеко от атомов подложки (более $3 \AA$ ); р-электроны именно этих атомов $\mathrm{Si}$ в $\mathrm{SiC}$ дают основной вклад в узкий и резкий пик плотности электронных состояний $3 C-\mathrm{SiC}(111) / \mathrm{Si}(111)$, находящийся в окрестности энергии Ферми. Иными словами, граница раздела $3 C-\mathrm{SiC}(111) / \mathrm{Si}(111)$ должна обладать необычными электрофизическими свойствами, в частности она должна хорошо проводить электрический ток. Измеренные эллипсометрические спектры показывают, что проводимость границы раздела только в $\sim 2$ раза меньше по сравнению с таким металлом, как свинец, при частотах электрического поля > 700 ТГц. При более низких частотах проводимость уменьшается.

Совершенно очевидно, что эта граница должна обладать и рядом необычных магнитных свойств. Как известно, характерными особенностями полуметаллов являются слабое перекрытие валентной зоны и зоны проводимости и то, что носители заряда в них отличаются большой подвижностью и малой эффективной массой. Все полуметаллы являются диамагнетиками. Основной вклад в величину магнитной восприимчивости вносят электроны валентной зоны полуметалла. Малая эффективная масса носителей заряда обусловливает большое значение магнитной восприимчивости. При низких температурах в полуметаллах должна наблюдаться осциллирующая зависимость магнитной восприимчивости от напряжённости магнитного поля (эффект де Гааза-ван Альфена) и ряд других квантовых явлений.

В задачи работы входили:

- регистрация полевых зависимостей статической магнитной восприимчивости;

- экспериментальная реализация условий „сильного поля“" $\left(\omega_{c} \tau=\mu B \gg 1\right.$, где $\tau$ и $\mu-$ транспортное время и подвижность носителей, $\omega_{c}$ - циклотронная частота, $B$ - магнитная индукция) с целью измерения магнитных характеристик данных образцов и возможного в них обнаружения сосуществования макроскопических квантовых эффектов различной природы при комнатной температуре. 
Технологические параметры образцов

\begin{tabular}{|c|c|c|c|c|c|c|}
\hline \multirow{2}{*}{$\begin{array}{l}\text { Технологический } \\
\text { номер образца }\end{array}$} & \multirow{2}{*}{ Подложка } & \multirow{2}{*}{$\begin{array}{l}\text { Условия } \\
\text { синтеза }\end{array}$} & \multirow{2}{*}{$\begin{array}{l}\text { Температура } \\
\text { легирования }\end{array}$} & \multicolumn{2}{|c|}{$\begin{array}{c}\text { Тип проводимости, } \\
\text { концентрация носителей заряда }\end{array}$} & \multirow{2}{*}{$\begin{array}{l}\text { Транзисторная } \\
\text { структура }\end{array}$} \\
\hline & & & & до легирования & после легирования & \\
\hline Б5 & $\begin{array}{c}p-\mathrm{Si}, \\
50 \mathrm{OM} \cdot \mathrm{cm}, \\
(100)\end{array}$ & $\begin{array}{l}T=1250^{\circ} \mathrm{C}, \\
t=20 \mathrm{мин}, \\
P=0.05 \text { Торp, } \\
I_{c o}=8 \mathrm{sccm}, \\
\%{ }_{\mathrm{SiH} 4}=0.25 \%\end{array}$ & $1100^{\circ} \mathrm{C}$ & $\begin{array}{l}\text { Компенсированный, } \\
\quad \sim 5 \cdot 10^{16} \mathrm{~cm}^{-3}\end{array}$ & $\begin{array}{c}p \text {-тип, } \\
>1 \cdot 10^{19} \mathrm{~cm}^{-3}\end{array}$ & Меза \\
\hline$\Phi 3$ & $\begin{array}{c}n-\mathrm{Si}, \\
20 \mathrm{OM} \cdot \mathrm{cm}, \\
(111)\end{array}$ & $\begin{array}{l}T=1290^{\circ} \mathrm{C}, \\
t=15 \mathrm{мин}, \\
P=2.3 \mathrm{Topp}, \\
I_{c o}=12 \mathrm{sccm} \\
\%{ }_{\mathrm{SiH} 4}=0.25 \%\end{array}$ & $1100^{\circ} \mathrm{C}$ & $\begin{array}{c}p \text {-тип } \\
\sim 4 \cdot 10^{17} \mathrm{~cm}^{-3}\end{array}$ & $\begin{array}{c}p \text {-тип, } \\
>1 \cdot 10^{19} \mathrm{~cm}^{-3}\end{array}$ & Меза \\
\hline$\Phi 4$ & $\begin{array}{c}n-\mathrm{Si}, \\
20 \mathrm{OM} \cdot \mathrm{cm}, \\
(110)\end{array}$ & $\begin{array}{l}T=1290^{\circ} \mathrm{C} \\
t=15 \mathrm{мин} \\
P=2.3 \mathrm{Topp}, \\
I_{c o}=12 \mathrm{sccm} \\
\%{ }_{\mathrm{SiH} 4}=0.25 \%\end{array}$ & $900^{\circ} \mathrm{C}$ & $\begin{array}{c}p \text {-тип, } \\
\sim 6 \cdot 10^{17} \mathrm{~cm}^{-3}\end{array}$ & $\begin{array}{c}p \text {-тип, } \\
>1 \cdot 10^{19} \mathrm{~cm}^{-3}\end{array}$ & Планарная \\
\hline$\Phi 5$ & $\begin{array}{c}n-\mathrm{Si}, \\
50 \mathrm{OM} \cdot \mathrm{cm}, \\
(110)\end{array}$ & $\begin{array}{l}T=1280^{\circ} \mathrm{C} \\
t=15 \mathrm{мин} \\
P=2.6 \mathrm{Topp} \\
I_{c o}=12 \mathrm{sccm} \\
\% \mathrm{SiH}_{4}=0 \%\end{array}$ & $800^{\circ} \mathrm{C}$ & $\begin{array}{l}\text { Компенсированный, } \\
\quad \sim 1 \cdot 10^{18} \mathrm{~cm}^{-3}\end{array}$ & $\begin{array}{c}p \text {-тип, } \\
>1 \cdot 10^{19} \mathrm{~cm}^{-3}\end{array}$ & Планарная \\
\hline
\end{tabular}

Примечание. В качестве условий синтеза приведены: $T-$ температура синтеза, $t-$ время синтеза, $P-$ давление CO, $I_{c o}-$ поток CO, \% ${ }_{\mathrm{SiH} 4}-$ объемный процент силана $\left(\mathrm{SiH}_{4}\right)$. Концентрация носителей определялась по данным емкостных измерений.

\section{2. Методика эксперимента}

\section{1. Получение экспериментальных образцов и их подготовка к магнитным измерениям}

В рамках настоящего исследования использовались образцы наномасштабных слоев $\mathrm{SiC}$, синтезированных на поверхностях (100), (110) и (111) монокристаллического $\mathrm{Si} p$-типа проводимости (легированного бором) и $n$-типа проводимости (легированного фосфором) методом согласованного замещения атомов. Параметры синтеза наномасштабных слоев $\mathrm{SiC}$ на $\mathrm{Si}$ приведены в таблице. Толщины слоев были $\sim(90-100)$ нм. Затем слои $\mathrm{SiC}$ были легированы бором. Легирование проводилось в условиях неравновесной диффузии из газовой фазы в избыточном потоке кремниевых вакансий с поверхности полученных образцов карбида кремния на кремнии.

В результате на поверхности образцов были сформированы транзисторные структуры. Параметры легированных бором образцов приведены в таблице. Структуры были получены на всех 4 образцах. Их характеристики также приведены в таблице. На образце Ф3 предварительно была вытравлена мезаструктура (высотой $\sim 500$ нм) в холловской топологии, а на двух образцах $\Phi 4$ и Ф5 использовалась планарная технология. Отметим, что на транзисторной структуре образца Б5, выращенной на $\mathrm{Si}$ (100), никаких интересных эффектов, речь о которых пойдет далее, обнаружено не было. Причина заключается в том, что образование кремния в состоянии полуметалла связано со „схлопыванием“ исходной решетки материала $\mathrm{Si}$ в кубическую решетку SiC. При „схлопывании“ решетки образуются высокие давления, о чем мы говорили выше. Этот процесс происходит только при росте на поверхности (111). Подробно это описано в работах $[3-7,9,10]$. На поверхности $\mathrm{Si}$ (100) иначе происходят рост и усадка материала при превращении $\mathrm{Si}$ в $\mathrm{SiC}$. Столь высоких давлений при этом не возникает, и соответственно $\mathrm{Si}$ в состоянии полуметалла практически не образуется. Поэтому далее этот образец мы рассматривать и описывать не будем. Теория и экспериментальные исследования роста $\mathrm{SiC}$ на $\mathrm{Si}$ (100) методом согласованного замещения атомов изложены в работе [11].

Холловская топология структур, выполненных в рамках планарной технологии, имеет следующие параметры: каждый чип имеет размеры $5 \times 5$ мм; внутри каждого чипа располагаются 12 полевых транзисторных структур. Холловская топология структуры, выполненной по мезатехнологии на образце $\Phi 3$, имеет следующие параметры: каждый чип имеет размеры $15 \times 5$ мм; внутри каждого чипа располагаются 7 полевых транзисторных структур.

Далее нами проводились измерения магнитных характеристик образов $Ф 3, \Phi 4$ и $Ф 5$. 


\section{2. Методика регистрации полевых зависимостей статической магнитной восприимчивости в структурах SiC на поверхности монокристаллического кремния}

Экспериментальные исследования проводились путем измерения статической магнитной восприимчивости в диапазоне напряженностей магнитных полей $H=0-11$ кЭ при комнатной температуре методом Фарадея на установке MGD 312 FG в автоматизированном режиме.

В основу метода Фарадея положено измерение силы взаимодействия материала с внешним магнитным полем, модуль индукции которого изменяется по „высоте“ образца.

В методе Фарадея связь между значением статической магнитной восприимчивости $\chi(T, B)$ и измеряемой силой $F_{0}(T, B)-$ „магнитным весом“ - определяется выражением

$$
\chi(T, B)=\frac{F_{0}(T, B)}{m B d B / d z} .
$$

Градиент индукции внешнего магнитного поля $d B / d z$ создается специальной формой полюсных наконечников магнита, а произведение $B d B / d z$ имеет одинаковое значение по всему объему, занимаемому образцом.

Для проведения измерений образец помещается в кварцевую чашку, которая соединяется с весами подвесом из того же материала. Сила $F_{0}(T, B)$ находится как разность силы взаимодействия с магнитным полем образца, помещенного в чашку, и силы, действующей на пустую чашку при тех же внешних условиях.

Калибровка установки проводилась с помощью эталонного образца, в качестве которого использовался монокристалл магнитно-чистого фосфида индия с восприимчивостью $\chi=-313 \cdot 10^{-9} \mathrm{~cm}^{3} /$ г. Высокая чувствительность балансного спектрометра MGD 312 FG, $10^{-9}-10^{-10} \mathrm{CGS}$, обеспечивала высокую стабильность калибровки значений $B d B / d z[12,13]$.

\section{3. Результаты экспериментальных исследований}

\section{1. Наблюдение эффекта перехода из парамагнитного в диамагнитное состояние}

В слабых магнитных полях для всех образцов мы наблюдали характерный гистерезис статической магнитной восприимчивости, что достаточно неожиданно, поскольку подобные явления подавлены при высоких температурах вследствие доминирования электрон-электронного взаимодействия. В образце $\Phi 5$, содержащем $p^{+}-n$-переход, мы обнаружили эффект последовательной смены состояний образца - переход из диамагнитного в парамагнитное и обратно в диамагнитное состояние. Этот эффект сохранился и при изменении направления внешнего магнитного поля (см. рис. 1, $a$ ).
Подобный „диа-пара-гистерезис“ магнитной восприимчивости известен как экспериментальная демонстрация эффекта Мейснера-Оксенфельда, идентифицирующего наличие свойства сверхпроводимости у исследуемого объекта. Этот, на первый взгляд, парадоксальный результат, полученный при комнатной температуре, может быть обусловлен либо возникновением диамагнитных токов вокруг микродефектов, которые генерируются в процессе получения структур $\mathrm{SiC}$ на кремниевой поверхности $[4,10]$, либо за счет существования на межфазной границе $\mathrm{SiC} / \mathrm{Si}$ кремния в состоянии полуметалла [10]. Возможно, данный эффект связан и с наличием краевых каналов, возникающих при последующем легировании бором, которые преимушественно ограничены дипольными центрами бора с отрицательной корреляционной энергией $[14,15]$. Таким образом, нами обнаружен эффект проявления высокотемпературной квантовой интерференции при исследовании полевой зависимости статической магнитной восприимчивости в наномасштабных слоях $\mathrm{SiC}$, выращенных на $\mathrm{Si}$ методом согласованного замещения атомов. Наличие этого эффекта свидетельствует о том, что в данном режиме слабое магнитное поле даже при комнатной температуре становится „полем сильным“. Иными словами, реализуется условие сильного поля, $\omega_{c} \tau=\mu B \gg 1$. Это означает, что подвижность носителей заряда $\mu=(e \tau) / m^{*}$ должна иметь высокое значение в слабом магнитном поле. Это в свою очередь говорит о том, что эффективная масса $\left(m^{*}\right)$ носителей заряда в образце должна быть малой, одновременно с большим значением времени релаксации $(\tau)[16]$. Таким образом, условно находясь в режиме „сильного поля“, в котором проявляются макроскопические явления квантовой интерференции, для оценок эффективной массы и подвижности мы можем воспользоваться формулой, приведённой в работе [17],

$$
H \approx 10^{5} T \frac{m^{*}}{m} \text {. }
$$

$\mathrm{C}$ помощью данного соотношения мы можем оценить значение эффективной массы носителей (двумерных дырок), а также их подвижность в выращенных слоях $\mathrm{SiC}$ на кремнии. Расчеты на основании зависимостей, представленных на рис. $1, a, b, c$, приводят к значениям: $m^{*} / m \leq 10^{-5}, \mu \leq 10^{2} \mathrm{M}^{2} / \mathrm{B} \cdot \mathrm{c}$.

Параметры обнаруженного нами гистерезиса статической магнитной восприимчивости в слабых магнитных полях и прежде всего значение внешнего магнитного поля, при котором значение статической восприимчивости обращается в нуль, хорошо согласуются с размерами исследуемых образцов. Таким образом, захват квантов магнитного потока на микродефект индуцирует возникновение вокруг него диамагнитного тока с соответствующим изменением величины и направления магнитного поля. Например, диамагнитный переход при значении магнитного поля 13 Э соответствует захвату кванта магнитного потока, $\Phi_{0}=h / 2 e$, на вакансионный микродефект, для которого $\Phi_{0}=B_{0} S$, где $B_{0}-$ значение 

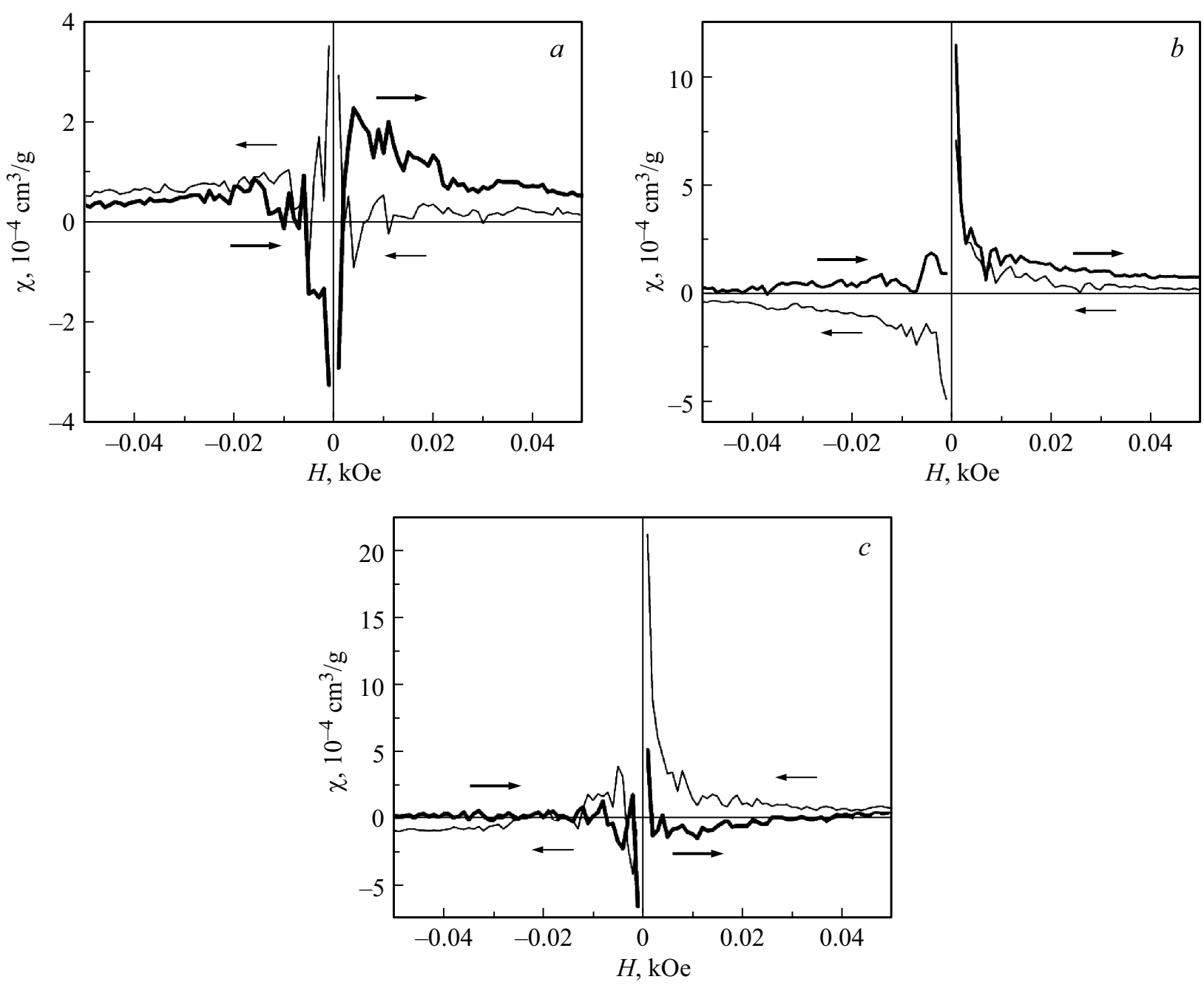

Рис. 1. Полевые зависимости статической магнитной восприимчивости с характерным гистерезисом в слабых магнитных полях для образцов $\Phi 5(a), \Phi 4(b)$ и $\Phi 3(c)$. Стрелками указано направление изменения внешнего магнитного поля.

индукции внешнего магнитного поля $13 \ni, S-$ площадь микродефекта (в случае вакансионного микродефекта размером $d=1.2$ мкм) $[10,11]$. Аналогично диамагнитные особенности, проявляющиеся в магнитных полях, кратных 300 Э, обусловлены захватом квантов магнитного потока на микродефекты с размерами $\sim 250$ нм.

В рамках предлагаемой модели критический ток, разрушающий диамагнетизм, соответствует 300 нА. Следует отметить: несмотря на то что в образцах, в которых отсутствуют $p^{+}-n$-переходы (см. рис. $1, b$ и $c$ ), характерный вид гистерезиса статической магнитной восприимчивости сохраняется, его „диа-, парамагнитные особенности“ сглаживаются и практически не наблюдаются. Это означает, что возникновение диамагнитных токов вокруг микродефектов и в краевых каналах исследуемых структур возможно только при наличии дополнительного электрического поля (поля $p^{+}-n$-перехода), которое подавляет электрон-электронные взаимодействия при наличии вблизи центров с отрицательной корреляционной энергией.

\section{2. Наблюдение осцилляций магнитной восприимчивости}

В исследуемых образцах $\mathrm{SiC} / \mathrm{Si}$ нами были обнаружены не только эффект гистерезиса статической магнитной восприимчивости, но и ее периодические осцилляции в зависимости от магнитного поля. Эти осцилляции мы связываем с эффектом Ааронова-Бома (рис. 2). Следует отметить, что в отличие от осцилляций де Гааза-ван Альфена (дГвА), которые проявляются в полевых зависимостях магнитной восприимчивости вследствие квантования Ландау, осцилляции Ааронова-Бома (АБ) возникают вследствие квантования магнитного потока при наличии замкнутых траекторий носителей заряда [18]. В отличие от осцилляций дГвА, периодичных в зависимости от обратного магнитного поля, период осцилляций АБ определяется магнитным потоком, $\Phi=n \Phi_{0}$, где $\Phi_{0}=h / 2 e$. Поэтому осцилляции дГвА и АБ могут быть независимо идентифицированы при измерении полевых зависимостей магнитной восприимчивости. 

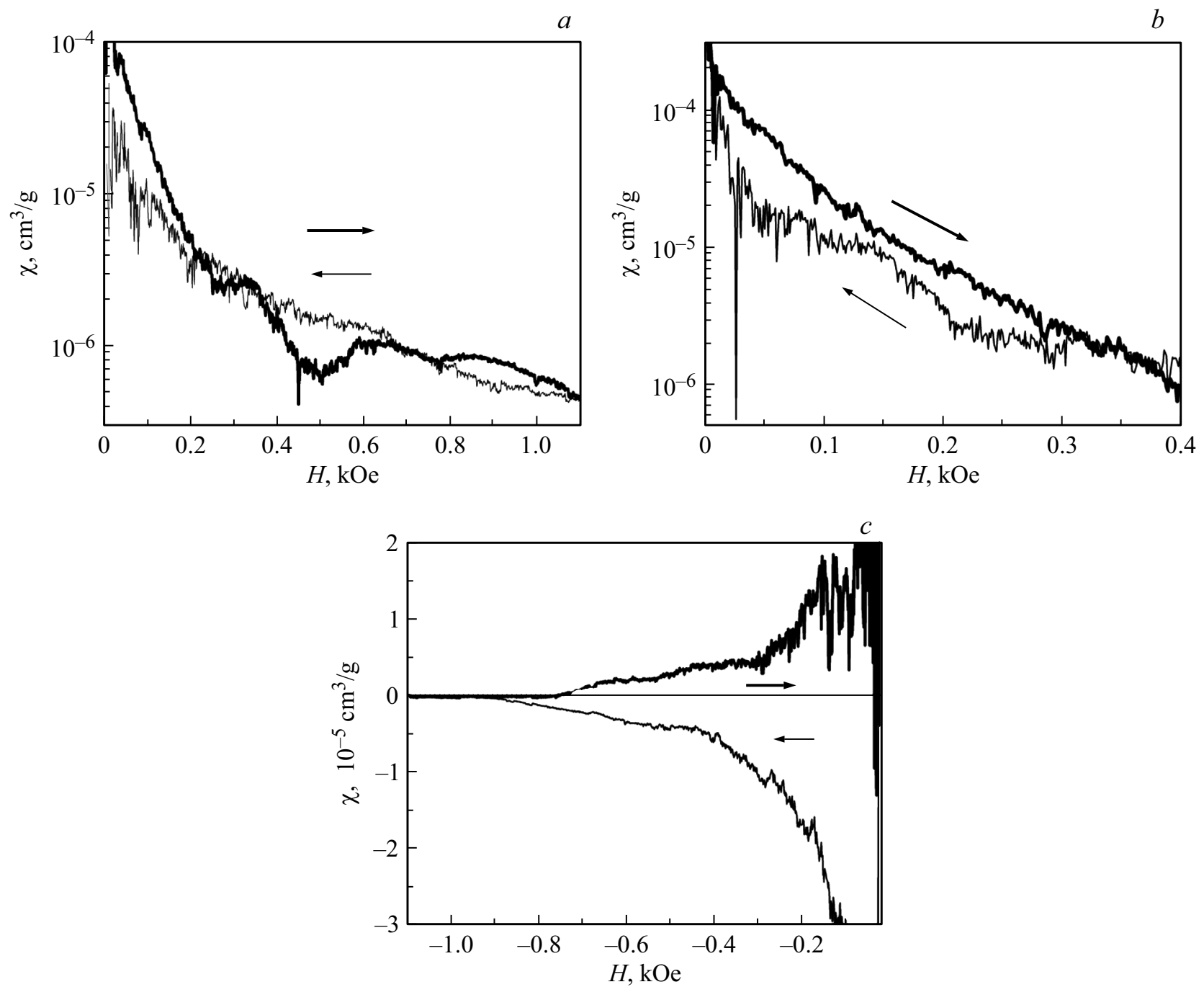

Рис. 2. Полевые зависимости статической магнитной восприимчивости, содержащие осцилляции Ааронова-Бома с большим периодом, которые, по-видимому, обусловлены наличием микродефектов в образцах $\Phi 5(a)$, Ф4 $(b)$ и Ф3 (c). Стрелками указано направление изменения внешнего магнитного поля.

В зависимостях, представленных на рис. 2-4, осцилляции дГвА достаточно сложно идентифицировать в слабых магнитных полях на фоне осцилляций АБ. Данный вопрос требует специальных экспериментов в условиях высокого разрешения по магнитному полю, а именно путем изменения шага при сканировании [12].

Как нами было уже отмечено, наблюдение АБ-осцилляций при комнатной температуре требует реализации условий сильного подавления электрон-электронного взаимодействия. Приведенные выше оценки характеристик образцов им соответствуют. Следует отметить хорошее соответствие значений периода АБ-осцилляций и значений магнитного поля, при котором наблюдается гистерезис магнитной восприимчивости и диамагнитные особенности. Эти данные в целом подтверждают предлагаемую модель возникновения макроскопических квантовых эффектов, базирующуюся на захвате оди- ночных квантов магнитного потока на микродефекты, наличие которых компенсируют упругие напряжения в полученных слоях $\mathrm{SiC} / \mathrm{Si}[10,11]$.

Так, в образце $Ф 5$, содержащем $p^{+}-n$-переход, возникновение осцилляций с большим периодом, 300 Э (см. рис. 3, $a$ ), по-видимому, обусловлено присутствием микродефектов с характерным размером 250 нм. При данной оценке мы учли, что период осцилляций Ааронова-Бома зависит от площади, на которую захватывается силовая линия магнитного поля: $\Phi_{0}=\Delta B S$, где $\Phi_{0}=h / 2 e-$ квант магнитного потока, $\Delta B-$ период осцилляций Ааронова-Бома, $S$ - площадь, на которую захватываются силовые линии магнитного поля. Отметим, что подобного рода дефектами, по нашему мнению, могут являться полые наноканалы и нанотрубки в $\mathrm{Si}$, покрытые слоем $\mathrm{SiC}$, присутствующие на границе пленкаподложка и образовавшиеся вследствие особенностей метода получения $\mathrm{SiC}$ [1-6]. 

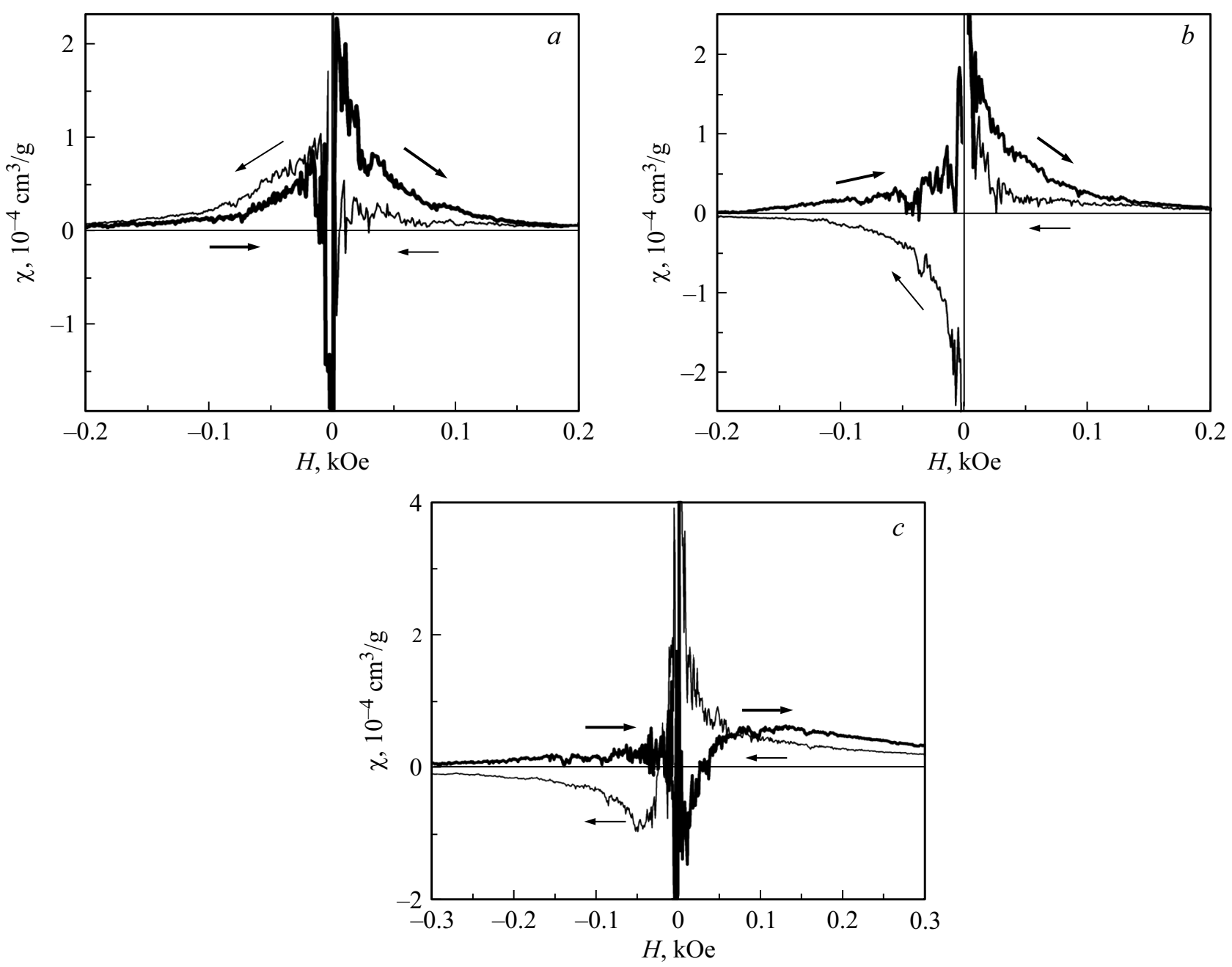

Рис. 3. Полевые зависимости статической магнитной восприимчивости, содержащие осцилляции Ааронова-Бома, которые, повидимому, обусловлены наличием пор на границе раздела $\mathrm{SiC}-\mathrm{Si}, \sim 1.5$ мкм, в образцах $Ф 5(a)$, Ф4 (b) и Ф3 (c). Стрелками указано направление изменения внешнего магнитного поля.

Следует также отметить, что остаточные диамагнитные токи могут приводить к АБ-осцилляциям магнитного момента, даже если длина свободного пробега $l$ будет меньше длины замкнутой траектории $L$. Однако при этом она должна быть меньше длины фазовой релаксации $L_{\varphi}[18,19]$. В противном случае следует ожидать, что АБ-осцилляции будут в значительной степени нивелированы в полевых зависимостях магнитной восприимчивости вследствие электрон-электронного взаимодействия, что характерно для металлических наноструктур. Это означает, что исследования роли остаточных диамагнитных токов, ответственных за возникновение АБ-осцилляций магнитной восприимчивости, целесообразно проводить, используя сверхпроводящие, диэлектрические, полупроводниковые и металлические наноструктуры, в которых отношение длины образца к длине фазовой релаксации будет достаточно малым. Принимая во внимание сказанное выше, можно утверждать, что наносандвичи на основе структур $\mathrm{SiC}$ на поверхности монокристаллического кремния представ- ляют особый интерес для таких исследований, поскольку их электрические и магнитные свойства зависят от величины внешнего магнитного поля, что позволяет изменять величину $L / L_{\varphi}$ в ходе измерений полевых зависимостей магнитной восприимчивости.

Аналогичные осцилляции Ааронова-Бома с большим периодом наблюдались в образцах в отсутствие $p^{+}-n$ перехода (см. рис. $3, b$ и $c$ ). Однако их менее выраженный характер указывает на меньшее количество больших микродефектов, с размерами 250 нм, что подтверждается данными структурных исследований $[1-7,10]$.

Второй тип осцилляций Ааронова-Бома, проявляющийся в полевых зависимостях статической магнитной восприимчивости, характеризуется периодом $\sim 13 \ni$ и преимущественно наблюдается в слабых магнитных полях (рис. 4, $a-c$ ). Проведенные оценки, если принять во внимание период осцилляций, показывают, что они, по-видимому, обусловлены наличием вакансионных микродефектов с характерным размером $\sim 1.5$ мкм. Следует отметить, что аналогичный размер имеют поры, 

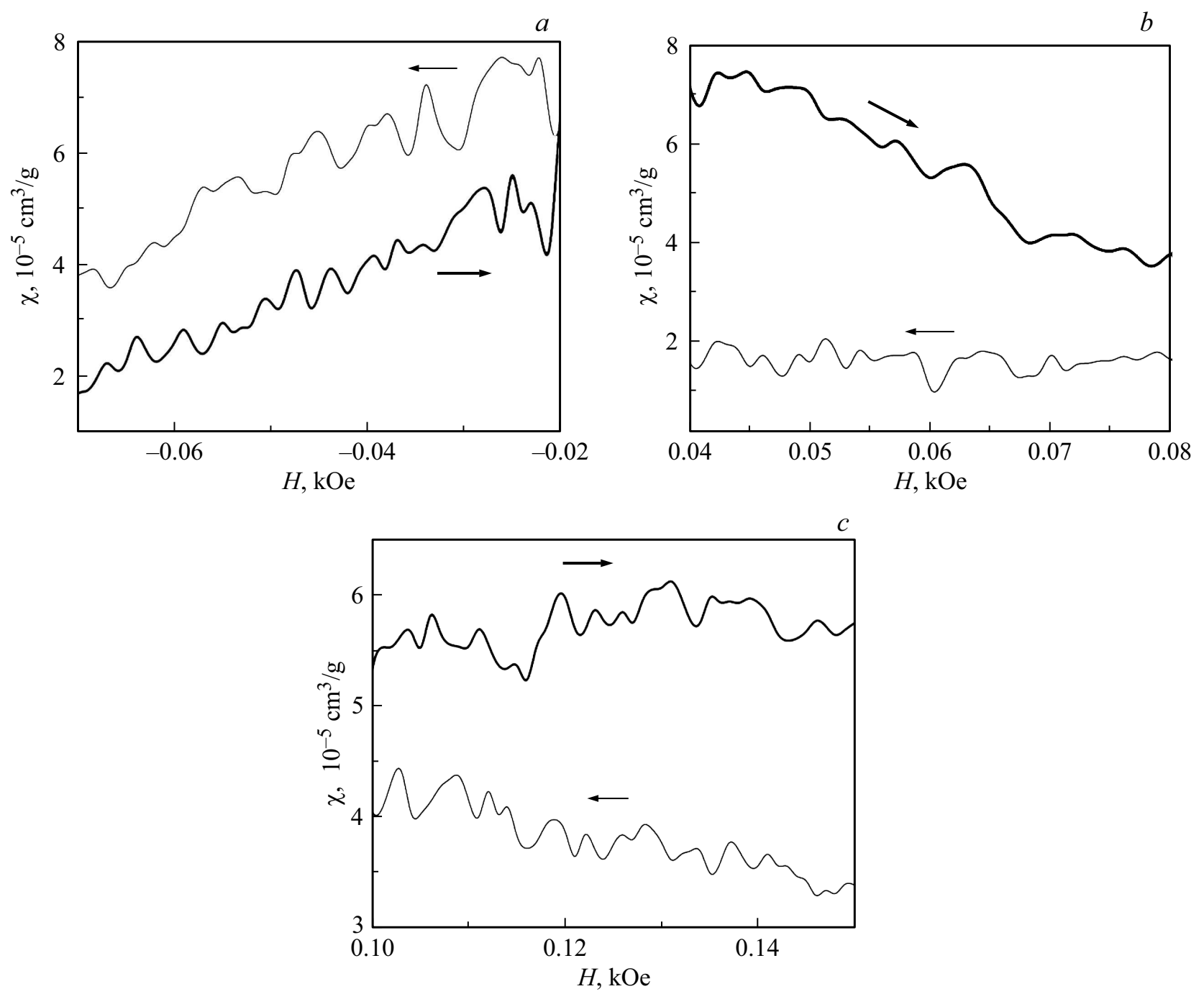

Рис. 4. Полевые зависимости статической магнитной восприимчивости, содержащие осцилляции Ааронова-Бома с малым периодом, которые, по-видимому, обусловлены захватом одиночных квантов магнитного потока на краевые каналы в образцах $\Phi 5(a), \Phi 4(b)$ и $\Phi 3(c)$. Стрелками указано направление изменения внешнего магнитного поля.

образующиеся на поверхности монокристаллического кремния под слоем $\mathrm{SiC}$ в процессе синтеза $\mathrm{SiC}$ методом замещения атомов $[1-7,10]$.

Рассмотренные выше осцилляции Ааронова-Бома модулируют более мелкие осцилляции с коротким периодом 2 Э, которые наблюдаются в широком диапазоне внешнего магнитного поля (рис. 4, $a-c$ ). Природа этих осцилляций, по-видимому, обусловлена захватом одиночных квантов магнитного потока на краевые каналы исследуемых структур. При этом следует учитывать, что длина краевого канала, опоясывающего подобные структуры, соответствует $10^{-2}$ м при ширине в несколько нанометров [13]. При данных условиях эффект АароноваБома наблюдается вследствие генерации магнитного момента, осциллирующего в зависимости от величины внешнего магнитного поля с периодом захвата одиночных квантов магнитного потока: $\Phi_{0}=\Delta B S$. Более того, захват одиночных квантов магнитного потока на краевые каналы прямо или через площадь образца и последующий транспорт силовых линий магнитного поля к краям образца может приводить к возникновению квантового эффекта Фарадея. Эффект Фарадея в свою очередь будет приводить к генерации соответствующей эдс, осциллирующей в зависимости как от внешнего магнитного поля, так и от тянущего тока типа истоксток [13].

\section{4. Заключение}

Таким образом, в результате экспериментальных исследований, было обнаружено следующее.

- Возникновение эффекта квантования магнитного момента в структурах $\mathrm{SiC}$, выращенных методом согласованного замещения атомов на $\mathrm{Si}(110)$ и $\mathrm{Si}(111)$; квантование магнитного момента проявилось в наблюдении 
осцилляций Ааронова-Бома в полевых зависимостях статической магнитной восприимчивости, период которых определяется параметрами микродефектов, формирующихся в процессе получения структур, а также захватом одиночных квантов магнитного потока на их краевые каналы.

- Образование гистерезиса статической магнитной восприимчивости при комнатной температуре в слабых магнитных полях в структурах $\mathrm{SiC}$, выращенных методом согласованного замещения атомов на $\mathrm{Si}$ (110) и $\mathrm{Si}$ (111), интерпретировано нами как проявление эффекта Мейснера-Оксенфельда. Причиной, ведущей к возникновению данного эффекта, по нашему мнению, является подавление электрон-электронного взаимодействия электрическими полями, возникающими как от микродефектов, состоящих из дипольных центров с отрицательной корреляционной энергией, так и от дипольных центров с отрицательной корреляционной энергией, ограничивающих краевые каналы структур $\mathrm{SiC} / \mathrm{Si}$.

- В структурах $\mathrm{SiC}$, выращенных на $\mathrm{Si}$ (100), эти эффекты обнаружены нами не были, что связывается нами с иным механизмом образования $\mathrm{SiC}$ на поверхности (100) Si.

\section{Информация об участии в исследованиях}

Часть исследований, а именно синтез пленок, проводился с использованием оборудования уникальной научной установки „Физика, химия и механика кристаллов и тонких пленок“ ФГУП ИПМаш РАН (Санкт-Петербург).

\section{Финансирование работы}

Работа выполнена при финансовой поддержке гранта РНФ (грант № 20-12-00193).

\section{Конфликт интересов}

Авторы заявляют, что у них нет конфликта интересов.

\section{Список литературы}

[1] С.А. Кукушкин, А.В. Осипов. ФТТ, 50, 1188 (2008).

[2] С.А. Кукушкин, А.В. Осипов. ДАН, 444, 266 (2012).

[3] С.А. Кукушкин, А.В. Осипов. Изв. РАН. Механика твердого тела, № 2, 122 (2013).

[4] S.A. Kukushkin, A.V. Osipov. J. Phys. D: Appl. Phys., 47 (31), 313001 (2014).

[5] С.А. Кукушкин, А.В. Осипов, Н.А. Феоктистов. ФТТ, 56, 1457 (2014).

[6] S.A. Kukushkin, A.V. Osipov. J. Phys. D: Appl. Phys., 50 (46), 464006 (2017).

[7] Л.М. Сорокин, Н.В. Веселов, М.П. Щеглов, А.Е. Калмыков, А.А. Ситникова, Н.А. Феоктистов, А.В. Осипов, С.А. Кукушкин. Письма ЖТФ, 34 (22), 88 (2008).

[8] F. Iacopi, G. Walker, L. Wang, L. Malesys, S. Ma, B.V. Cunning, A. Iacop. Appl. Phys. Lett., 102, 011908 (2013).
[9] S.A. Kukushkin, A.V. Osipov. Physica B: Condens. Matter, 512, 26 (2017).

[10] С.А. Кукушкин, А.В. Осипов. Письма ЖТФ, 46 (22), 3 (2020).

[11] S.A. Kukushkin, A.V. Osipov, I.P. Soshnikov. Rev. Adv. Mater. Sci., 52, 29 (2017).

[12] В.В. Романов, В.А. Кожевников, В.А. Машков, Н.Т. Баграев. ФТП, 54, 1331 (2020).

[13] N.T. Bagraev, V.Yu. Grigoryev, L.E. Klyachkin, A.M. Malyarenko, V.A. Mashkov, V.V. Romanov, N.I. Rul'. Low Temp. Phys./Fizika Nizkikh Temperatur, 43, 132 (2017).

[14] N.T. Bagraev, V.A. Mashkov. Solid State Commun., 51, 515 (1984).

[15] N.T. Bagraev, V.A. Mashkov. Solid State Commun., 65, 1111 (1988).

[16] G. Landwehr, J. Gerschütz, S. Oehling, A. Pfeuffer-Jeschke, V. Latussek, C.R. Becker. Physica E, 6, 713 (2000).

[17] С.В. Вонсовский. Магнетизм (М., Наука, 1971).

[18] Й. Имри. Введение в мезоскопическую физику (М., Физматлит, 2002).

[19] S. Datta. Electronic transport in mesoscopic systems (University Press, Cambridge, 2005).

Редактор Л.В. Шаронова

\section{Magnetic properties of thin epitaxial SiC layers grown by atoms substitution method on monocrystalline silicon surfaces}

\author{
N.T. Bagraev ${ }^{1,2}$, S.A. Kukushkin ${ }^{1}$, A.V. Osipov, ${ }^{1}$, \\ V.V. Romanov ${ }^{3}$, L.E. Klyachkin ${ }^{2}$, \\ A.M. Malyarenko ${ }^{2}$, V.S. Khromov ${ }^{1,2}$ \\ ${ }^{1}$ Institute for Problems in Mechanical Engineering, \\ Russian Academy of Sciences, \\ 199178 St. Petersburg, Russia \\ ${ }^{2}$ loffe Institute, \\ 194021 St. Petersburg, Russia \\ ${ }^{3}$ Peter the Great St. Petersburg Polytechnic University, \\ 195251 St. Petersburg, Russia
}

\begin{abstract}
The work carried out represents a cycle of experimental studies, namely, measurements and analysis of static magnetic susceptibility field dependencies in samples of singlecrystal SiC thin films grown on (100), (110) and (111) surfaces of monocrystalline $\mathrm{Si}$ by atoms substitution methods caused by chemical reaction of silicon with carbon monoxide gas $(\mathrm{CO})$. The studies of the $\mathrm{SiC}$ structures grown on $\mathrm{Si}(110)$ and $\mathrm{Si}$ (111) are found to reveal two quantum effects occurred in weak magnetic fields at room temperature. These effects are: firstly, formation of hysteresis of static magnetic susceptibility, and secondly, the occurrence of the Aharonov-Bohm oscillations in field dependencies of static magnetic susceptibility. The formation of the first effect is associated with the Meissner-Ochsenfeld effect, and the second - with presence in these structures under a $\mathrm{SiC}$ layer microdefects in the form of nanotubes and micropores formed during the structures synthesis. In the $\mathrm{SiC}$ structures grown on $\mathrm{Si}$ (100) surface, these effects were not detected, which is associated with another mechanism of $\mathrm{SiC}$ formation on the $\mathrm{Si}$ (100) surface.
\end{abstract}

